\title{
The Collective Action Problem: Within-Group Cooperation and Between-Group Competition in a Repeated Rent-Seeking Game
}

\section{GUILLAUME CHEIKBOSSIAN}




\title{
The Collective Action Problem: Within-group Cooperation and Between-group Competition in a Repeated Rent-Seeking Game.*
}

\author{
Guillaume Cheikbossian \\ Toulouse School of Economics (GREMAQ) \\ Université des Sciences Sociales \\ Manufacture des Tabacs - Bât F \\ 21 Allée de Brienne \\ 31000 Toulouse - France
}

Tel: (+33) (0)5 61128628

Fax: (+33) (0)561225563

September 24, 2009

${ }^{\star}$ E-mail: gcheikbo@univ-tlse1.fr

I thank Léonard Dudley, Patrick Gonzalez, Bruno Jullien, Laurent Linnemer, Nicolas Marceau, Wilfried SandZantman, Nicolas Treich, Etienne Wasmer and especially Philippe Mahenc, Thomas Mariotti and Javier Ortega for comments and suggestions. I also thank for useful discussions seminar participants at the Université de Montpellier, Université de Toulouse, Université de Montréal, UQAM (Montréal), Université Laval (Québec), Canadian Economic Association (Montréal) and ESEM 2006 (Vienna). Finally, I should also like to thank two anonymous referees and an anonymous associate editor for their comments and suggestions. This paper has been greatly improved by them. The usual disclaimer applies. 
Abstract: This paper analyzes the ability of group members to cooperate in rent-seeking activities in a context of between-group competition. For this purpose, we develop an infinitely repeated rent-seeking game between two groups of different size. We first investigate Nash reversion strategies to support cooperative behavior in a given group before analyzing double-edge trigger strategies which have the property that cheating on the cooperative agreement in a given group is followed by non-cooperation in this group and cooperation in the rival group. The main conclusion is that the set of parameters for which cooperation can be sustained within the larger group as a subgame perfect outcome is as large as that for which cooperation can be sustained in the smaller group. Hence, in contrast with Olson's (1965) celebrated thesis but in accordance with many informal and formal observations, the larger group is as effective as the smaller group in furthering its interest.

Keywords: Collective action, Rent-seeking, Within-group cooperation, Between-group competition, Repeated game.

JEL Classification: D72; D74; C72; C73 


\section{Introduction}

Olson's (1965) celebrated theory argues that larger groups are less effective than smaller groups in furthering their interest. The reason is that the incentive to free-ride on the actions of the others is more pervasive when group size is large due to a smaller perceived impact of individual defection. Olson's thesis stimulated an important literature and has been criticized on several fronts. First, while individuals contribute less in large groups, this does not necessarily imply that there are less effective. Chamberlin (1974) and McGuire (1974) first pointed out that Olson's thesis of a negative relationship between effective collective action and group size holds when the prize is private but is overturned when the prize is public and not divisible among group members. Second, cooperation may be achieved in a repeated-game setup through the use of an appropriate trigger strategy (e.g., Axelrod 1981). However, political scientists seem to agree that decentralized strategies of reciprocity may fail to enforce cooperation in large groups where mutual monitoring may be difficult (e.g., Taylor 1976, Olson 1982, Hardin 1982). Bendor and Mookherjee (1987) formalize this intuition and represent ongoing collective action as a repeated prisoner's dilemma game. In their framework, trigger strategies are shown to be indeed less effective in inducing mutual cooperation when group size is large or when there is imperfect monitoring. Olson's main conclusions then reappear in a repeated game setup regardless of the public or private nature of the collective good.

Empirically, contrary to Olson's insight, size seems to be an asset in many situations. For instance, Checchi and Lucifora (2002), analyzing a sample of 14 European countries, show that there is a positive correlation between union size and union influence. Similarly, the ability of farmer's unions to influence the European Common Agricultural Policy is generally explained by their large size and capacity to organize broadly both at the national and European level (e.g. Keeler 1996). The leading EU farm lobby, the Comité des Organisations Professionnelles Agricoles (COPA), is one of the oldest and most powerful lobby groups in Brussels, which is reflected by the resources made available to it. It has a secretariat staffed by fortyfive to fifty people (Davis 2003, 244). By comparison, the largest lobby group defending EU consumers' interests (Bureau Européen des Unions de Consommateurs, BEUC) has a permanent staff of only ten to fifteen in its Brussels office (Davis 2003, 245) while that available to the eight largest environmental groups (internally referred to as the G-8) amount to no more than twenty to thirty persons (Long 1998, 110). Finally, government transfers targeted at specific groups are, in general, increasing in the size of the groups (see, for example, Congleton and Shugart 1990 for pensions and retirement benefits, Kristov, Lindert and McClelland 1992 for social insurance benefits, and Potters and Sloof 1996 for a comprehensive survey on empirical analysis of interest groups' influence).

In fact, size seems to be an important resource especially when groups compete with each other for 
political influence or when they compete to secure a resource. For instance, Esteban and Ray (2001) notice that the predictions of traditional collective action theory run counter to the Roman maxim: "divide and conquer"; a strategy that proved to be successful in numberless historical circumstances. Regarding the economic arena, many situations also involve a competition between different organizations but also between subunits within the same private or public organization. For example, Hills and Mahoney (1978) shows that budgeting and resource allocation in US State Universities is due to the resolution of conflicts between academic departments rather than to an optimizing bureaucratic decision process. More recently, Scharfstein (1998) find evidence that conflicts and influence activities affect the allocation of capital across divisions in multi-divisional firms. If Olson's thesis is to be accepted, we should observe that smaller university departments or smaller divisions in conglomerates receive more - and larger ones receive less resources. We do not seem to observe such features in reality. ${ }^{1}$

Here, we set up a simple model of collective action which explains why larger groups may be at least as effective as smaller groups. Our analysis is based on two key features. First, we depict collective action as a repeated game so that within-group cooperation may be maintained through the use of a simple trigger strategy. Second, while most collective goods theories deal with actions of a single group, we analyze the problem of collective action in the presence of two opposing groups. In this context, free-riding might be extremely costly since it makes non-cooperative groups more vulnerable to the actions of competing groups, an intuition that is supported by a body of experimental evidence in social psychology. ${ }^{2}$

More specifically, we build a simple rent-seeking game à la Tullock (1980) and Nitzan (1991) where two unequally-sized groups compete for a private prize divisible both at the group level and at the individual level. The sum of individual efforts contributed in a group determines the proportion of the rent allocated to each group and then, since individual contributions are not observable by anybody, each group's share is equally distributed among group members. In the one-shot game, because of the free-rider problem, the more populous group spends less on rent-seeking activities and, consequently, receives a lower share of the rent as predicted by Olson's theory. In the repeated game, cooperation within one group, or both, can be maintained through the use of a trigger strategy if players are sufficiently patient. Ease of cooperation, in a particular group, is then measured by the lowest discount factor that supports the optimal level of group

\footnotetext{
1 However, Rajan, Servaes and Zingales (2000), analyzing a large sample of US firms, show that smaller divisions receive more resources relative to their productivity and investment opportunities. But if Olson's thesis is to be taken at face-value, we should observe that larger units receive more resources in absolute terms.

2 Several empirical studies indeed show that tournament-based group incentives lead to higher outputs than all other mechanisms investigated (see, e.g., Bornstein, Erev and Rozen 1990, Erev, Bornstein and Galili 1993, Bornstein, Gneezy and Nagel 2002).
} 
effort as a subgame perfect outcome. Furthermore, the critical value of the discount factor associated with a given group depends on the level of collective action of the rival group. This is because the singleperiod payouts of cooperation, non-cooperation and defection in a given group depend on the outcome of between-group competition, which in turn depends on the behavior of the members of the rival group.

The analysis focuses on the construction of two types of stationary subgame perfect equilibria (SSPE), one in which there is cooperation within the two groups and the other in which there is cooperation within only one group: the larger group or the smaller group. We first suppose that the members of each group follow Friedman's Trigger Strategies (FTSs) which use infinite Nash reversion within the corresponding group as punishment to provide incentives. Because group members' payoffs in a given group are contingent on the behavior of the members of the rival group through the intergroup competition, we begin by considering that the members of the rival group have a fixed behavior over time - they fully cooperate or do not cooperate with each other. We then show that within-group cooperation is less difficult as the number of fellow member rises no matter the behavior of the members of the rival group. Larger groups are characterized both by a greater temptation to cheat and by a greater penalty associated with defection because the free-rider problem becomes more severe in the non-cooperative equilibrium as membership rises. In the presence of competing groups, the severity of the penalty for cheating increases more rapidly because it makes the group more vulnerable to the actions of the rival group even though its members do not cooperate. Holding constant the size of each group and making a comparison across groups, we also find that the larger group can more easily sustain cooperation when there is cooperation within the smaller group. But this result is overturned when there is non-cooperation within the rival group. Nash punishment is less severe for the smaller group but the relative benefits of cooperation are disproportionately higher for this group because its opponent is extremely vulnerable to the free-rider effects due to its large size.

We also show that cooperation can be more easily sustained with FTSs when facing a non-cooperative rival group, which is rather intuitive. This actually explains why, in general, cooperation cannot be sustained as a subgame perfect outcome using FTSs within the two groups except for a small range of discount factors close to 1 . Hence, continuing with FTSs, we would need to assume that the members of one group never cooperate with each other. However, if there is permanent reversion to the noncooperative equilibrium in the first group, the members of the other group could, in their turn, to support cooperative behavior. We thus construct Double-Edge Trigger Strategies (DETSs) which have the property that cheating on the agreement in the cooperative group is followed by non-cooperation in this group and cooperation in the rival group. Off the equilibrium path, the members of the rival group abide by the (new) cooperative agreement until cheating is detected in which case they revert back to the non-cooperative equilibrium for ever. 
Compared to the situation where the members of a given group use FTSs while the members of the rival group never cooperate with each other, DETSs involve harsher punishments because the members of a given group are always worse off in the presence of internal cooperation in the rival group. We indeed show that DETSs increase the range of discount factors for which cooperative behavior can be supported as a subgame perfect outcome in the larger group. However, the cooperation of the other group members is not a credible threat for the members of the smaller group because, as discussed above, cooperation (supported by Nash reversion) is more difficult to sustain in the larger group when facing a non-cooperative rival group. We finally show that, for the same range of discount factors, cooperation can be sustained as a SSPE either in the smaller group through FTSs or in the larger group through DETSs. Therefore, the larger group is as likely to maintain cooperation as the smaller group.

Our paper is related to the large literature on rent-seeking theory ${ }^{3}$ and, in particular, to the analysis of collective rent-seeking or group contests initiated by Nitzan (1991). ${ }^{4}$ This literature focuses on the aggregate level of rent dissipation in a static setting while our paper focuses on the ability of competing groups to overcome their free-riding problem in a repeated game setting. More closely related, in its focus, is the work by Esteban and Ray (2001), which analyzes collective action with multiple groups in a contest game where the contested prize has mixed public-private characteristics. They show that if the individual cost of contributing to group action is quadratic, or more convex, then larger groups are more effective no matter how private the prize is. This is because, in this case, the higher level of individual effort contributed in the smaller group (due to a reduced free-rider problem) is not sufficient to counterbalance the lower number of contributors. However, their analysis is also static and there is no scope for cooperation within groups competing against each other.

Our analysis is also related to the literature on tacit cooperation in repeated games. Leininger and Yang (1994) analyze a rent-seeking game in which contestants move sequentially over time. They show that the dynamic of the rent-seeking process may involve implicit collusion with less rent dissipation than in a static game. In the context of oligopoly, Lambson $(1984,1987)$ analyses the effect of an increase in the number of firms on their ability to maintain a cooperative outcome and shows that cooperation generally breaks down when the number of firms rises to infinity. Pecorino (1998) focuses on the effect of an increase in the number of firms on their ability to overcome free-riding in lobbying for tariffs. He concludes that maintaining cooperation is not necessarily more difficult as the number of firms rises. Again, the distinctive

\footnotetext{
${ }^{3}$ Following the seminal contribution of Tullock (1980), rent-seeking has been studied in various contexts such as risk aversion (e.g. Skaperdas and Gan 1995), asymmetric information (e.g. Wärneryd 2003), asymmetric valuations (e.g. Nti 1999) or multistage contests (e.g. Gradstein and Konrad 1999 or Yildirim 2005). For a survey, see Konrad (2009).

${ }^{4}$ More recent contributions on group contests include, among others, Davis and Reilly (1999) and Baik and Lee (2001).
} 
feature of our work is to analyze the effect of intergroup competition on within-group coordination in a repeated game setting.

This paper is organized as follows. In Section 2, we first outline a simple model of collective rent-seeking and characterize the single-period equilibrium when the members of each group act non-cooperatively in rent-seeking. In this Section, we also characterize group members' payoffs under cooperation depending on whether or not there is cooperation within the rival group. Section 3 explores the infinitely repeated game when group members use FTSs and when they use DETSs to support cooperative behavior. Finally, Section 4 concludes.

\section{The Model}

\subsection{The Stage Game}

We start by specifying the details of the stage game $G$. There are $N$ players divided in two groups $A$ and $B$ which have $n_{A}$ and $n_{B}$ members, respectively. We assume that it is prohibitively costly for individuals to move from one group to the other. The government implements a policy generating a divisible rent $Y$ and decides on the division of this pie among the two groups in response to the rent-seeking pressures and lobbying activities of the members of the groups. Let $e_{i j} \in \Re_{+}$be the rent-seeking expenditure/effort expended, at unit cost, by member $i$ of group $j$ and let $\mathbf{E} \in \Re_{+}^{N}$ be the vector of all individual rent-seeking efforts. Following much of the contest literature, we assume that the share allocated to group $j$ is given by the contest success function $p_{j}(\mathbf{E}): \Re_{+}^{N} \rightarrow[0,1]$ which has the Logit form

$$
p_{j}(\mathbf{E})=\left\{\begin{array}{lll}
E_{j} /\left(E_{A}+E_{B}\right) ; & \text { if } & \left(E_{A}, E_{B}\right) \neq(0,0) \\
1 / 2, & \text { if } \quad\left(E_{A}, E_{B}\right)=(0,0)
\end{array}\right.
$$

where $E_{j} \equiv \sum_{i=1}^{n_{j}} e_{i j}$ denotes the aggregate rent-seeking expenditures of group $j$. Hence, a group gets a share of the total rent that depends on the sum of expenditures of its members relative to the total expenditure. When nobody invests anything, the rent is equally shared between the two groups.

Individual contributions cannot be observed, and so the rent appropriated by each group is equally shared among its members. We also assume that individual preferences are represented by a twice differentiable and additively separable utility function $\pi_{i j}: \Re_{++}^{N} \rightarrow \Re_{+}$. Specifically, individual $i$ in group $j$ has the following utility

$$
\pi_{i j}(\mathbf{E})=\frac{p_{j}(\mathbf{E}) Y}{n_{j}}-e_{i j}
$$

We first analyze the one-period equilibrium outcome in which neither group exhibits any cooperation in among its members. Since there is no equilibrium where nobody invests anything, the optimal expenditure 
of a member of group $j$ must satisfy the following first-order condition ${ }^{5}$

$$
\frac{\sum_{i=1}^{n_{k}} e_{i k}}{\left[\sum_{i=1}^{n_{j}} e_{i j}+\sum_{i=1}^{n_{k}} e_{i k}\right]^{2}} \frac{Y}{n_{j}}=1, \quad k \neq j .
$$

Due to the public-good nature of this problem, first-order conditions only determine group expenditures. We look, however, for the symmetric equilibrium such that all members in a group provide the same effort. Let $e_{j}^{* *}$ (for $j=A, B$ ) be the common equilibrium level of individual effort in group $j$. The conditions for an equilibrium are then

$$
\frac{n_{k} e_{k}^{* *}}{\left[n_{j} e_{j}^{* *}+n_{k} e_{k}^{* *}\right]^{2}} \frac{Y}{n_{j}}=1, \quad j=A, B, \quad j \neq k .
$$

The solution to this system of equations is

$$
e_{j}^{* *}=\frac{n_{k}}{\left(n_{j}+n_{k}\right)^{2}} \frac{Y}{n_{j}}, \quad j=A, B, \quad j \neq k .
$$

From (1), the share allocated to group $j$ is then

$$
p_{j}\left(E_{j}^{* *}, E_{k}^{* *}\right)=\frac{n_{k}}{n_{j}+n_{k}}, \quad j \neq k .
$$

with $\left(E_{A}^{* *}, E_{B}^{* *}\right)$ denoting aggregate expenditures of groups $A$ and $B$ when there is non-cooperation within the two groups.

The group with fewer members gets the larger share of the total rent. In addition, the share allocated to a given group is decreasing in its size and increasing in the size of the rival group. Thus, when the collective prize is private and divisible among group members, the negative size effect due to free-riding dominates the positive size effect due to a larger number of contributors which is in accordance with the traditional collective action theory. Finally, it is worth pointing out that the larger group not only ends up with the lower share of the rent but must also divide this share by a larger number of claimants.

The payoff for each member of group $j$ is then

$$
\pi_{j}\left(E_{j}^{* *}, E_{k}^{* *}\right)=\frac{n_{k}\left(n_{j}+n_{k}-1\right)}{\left(n_{j}+n_{k}\right)^{2}} \frac{Y}{n_{j}}, \quad j=A, B, \quad j \neq k .
$$

In the absence of within-group cooperation, the members of the smaller group have a higher payoff than the members of the bigger group. Furthermore, individual payoff, within each group, is falling in the number of fellow members and increasing in the size of the rival group. This is because the free-rider problem within a particular group becomes more severe as membership rises.

\footnotetext{
${ }^{5}$ Note that the marginal return to an additional unit of individual rent-seeking effort (as well as to an additional unit of group rent-seeking effort) is decreasing in effort. Hence, each player's problem is strictly concave and the first-order conditions are both necessary and sufficient for characterizing the best-response functions of the players.
} 


\subsection{The Efficient Level of Group Effort}

We now consider a situation where there can be full within-group cooperation. In other words, the members of at least one group jointly choose their contributions so as to maximize their aggregate welfare.

Assume first that there is cooperation within each of the two groups. In the cooperative equilibrium, the members of group $j$ (for $j=A, B$ ) jointly maximize $\Pi_{j}=\sum_{i=1}^{n_{j}} \pi_{i j}=\left[p_{j}(\mathbf{E}) Y\right]-E_{j}$ with respect to $E_{j}$. The optimal level of aggregate expenditure of group $j$ must then satisfy the following first-order condition

$$
\frac{E_{k}}{\left[E_{j}+E_{k}\right]^{2}} Y=1, \quad k \neq j .
$$

Let $\widetilde{\widetilde{e}}_{j}$ (for $j=A, B$ ) be the common level of individual effort in group $j$ when there is cooperation within the two groups. It is easily checked that the solution of this system is

$$
\widetilde{\widetilde{e}}_{j}=Y / 4 n_{j}, \quad j=A, B
$$

The equilibrium share allocated to each group is then $p_{j}\left(\widetilde{\widetilde{E}}_{A}, \widetilde{\widetilde{E}}_{B}\right)=\frac{1}{2}$ for $j=A, B$ and with $\left(\widetilde{\widetilde{E}}_{A}, \widetilde{\widetilde{E}}_{B}\right)$ denoting aggregate expenditures of groups $A$ and $B$ when there is cooperation within the two groups.

Neither the sum total of individuals in both groups nor the distribution of individuals among these groups affect aggregate rent-seeking by each group. Hence, each group obtains half of the total rent in equilibrium. Indeed, because individual preferences are represented by a utility function that is additively separable and linear in $Y$ and in rent-seeking activities, within-group cooperation makes each group acting as it was a single agent. The equilibrium utility of each group member is then

$$
\pi_{j}\left(\widetilde{\widetilde{E}}_{j}, \widetilde{\widetilde{E}}_{k}\right)=\frac{Y}{4 n_{j}}, \quad j=A, B .
$$

Next, consider a situation in which there is cooperation in group $j$ only. In other words: (i) the members of group $j$ jointly maximize $\sum_{i=1}^{n_{j}} \pi_{i j}=\left[p_{j}(\mathbf{E}) Y\right]-E_{j}$ with respect to $E_{j}$, where $p_{j}(\mathbf{E})=E_{j} /\left[E_{j}+\sum_{i=1}^{n_{k}} e_{i k}\right]$ and, (ii) each member of group $k \neq j$ maximizes $\pi_{i k}=\left[p_{k}(\mathbf{E}) Y\right] / n_{k}-e_{i k}$ with respect to $e_{i k}$, where $p_{k}(\mathbf{E})=\sum_{i=1}^{n_{k}} e_{i k} /\left[E_{j}+\sum_{i=1}^{n_{k}} e_{i k}\right]$.

The optimal level of aggregate expenditure of group $j$ must satisfy the following first-order condition

$$
\frac{\sum_{i=1}^{n_{k}} e_{i k}}{\left[E_{j}+\sum_{i=1}^{n_{k}} e_{i k}\right]^{2}} Y=1 \quad k \neq j .
$$

The optimal expenditure of a non-cooperative member of group $k \neq j$ must satisfy the following first-order condition

$$
\frac{E_{j}}{\left[E_{j}+\sum_{i=1}^{n_{k}} e_{i k}\right]^{2}} \frac{Y}{n_{k}}=1 \quad j \neq k .
$$


We focus on symmetric equilibria, where all members of the non-cooperative group make the same level of effort. Let $\widetilde{e}_{j}$ and $e_{k}^{*}$ be the cooperative and non-cooperative level of individual effort within group $j$ and $k \neq j$, respectively. Then, the solution of the above system is

$$
\begin{aligned}
\tilde{e}_{j} & =\frac{n_{k}}{\left(n_{k}+1\right)^{2}} \frac{Y}{n_{j}}, \quad j \neq k, \\
e_{k}^{*} & =\frac{1}{\left(n_{k}+1\right)^{2}} \frac{Y}{n_{k}} .
\end{aligned}
$$

Observe that $\widetilde{e}_{j}=\left[n_{k}^{2} / n_{j}\right] e_{k}^{*}$ for $j \neq k$. In equilibrium, the share allocated to group $j$ is then

$$
p_{j}\left(\widetilde{E}_{j}, E_{k}^{*}\right)=\frac{n_{k}}{n_{k}+1} \quad j \neq k
$$

with $\left(\widetilde{E}_{j}, E_{k}^{*}\right)$ denoting aggregate expenditures when there is cooperation within group $j$ and noncooperation within group $k \neq j$. Note that the share of the rent allocated to group $j$ tends to 1 for $n_{k}$ large.

The equilibrium utility of each individual in group $j$ is then

$$
\pi_{j}\left(\widetilde{E}_{j}, E_{k}^{*}\right)=\left(\frac{n_{k}}{n_{k}+1}\right)^{2} \frac{Y}{n_{j}}, \quad j \neq k
$$

and the equilibrium utility of each individual in group $k \neq j$ is

$$
\pi_{k}\left(E_{k}^{*}, \widetilde{E}_{j}\right)=\frac{n_{k}}{\left(n_{k}+1\right)^{2}} \frac{Y}{n_{k}}
$$

By comparing the utility of each individual in each group under different scenarios, we can establish the following Lemma, which will prove useful later.

Lemma $1:$ For any $n_{j} \geq 2$ and $n_{k} \geq 2$, we have $\pi_{j}\left(\widetilde{E}_{j}, E_{k}^{*}\right)>\pi_{j}\left(\widetilde{\widetilde{E}}_{A}, \widetilde{\widetilde{E}}_{B}\right)$ and $\pi_{k}\left(E_{k}^{*}, \widetilde{E}_{j}\right)<$ $\pi_{k}\left(E_{A}^{* *}, E_{B}^{* *}\right)$ for $j=A, B$ and $j \neq k .^{6}$

The members of a given group, no matter whether they cooperate or not, have a higher (respectively lower) payoff when facing a non-cooperative (respectively cooperative) rival group. In other words, cooperation of the others is always detrimental to the members of a given group. First, the gains from cooperation are larger when facing a non-cooperative rival group. Second, non-cooperation is less costly when facing a rival group which is also vulnerable to the free-rider problem.

\section{Within-Group Cooperation and Between-Group Competition}

\subsection{Preliminaries}

We now define the discounted infinitely repeated game denoted $G^{\infty}(\delta)$ where $\delta \in(0,1)$ is the common discount factor per period. While individual contributions cannot be observed, the aggregate level of

\footnotetext{
${ }^{6}$ All the proofs are in the Appendix.
} 
contributions made by each group is however perfectly observed by any member of the two groups. If $E_{j}^{t}$, for $j=A, B$, is the aggregate level of contributions of the members of group $j$ in period $t$, then $\left(\left(E_{A}^{0}, E_{B}^{0}\right),\left(E_{A}^{1}, E_{B}^{1}\right), \ldots,\left(E_{A}^{t-1}, E_{B}^{t-1}\right)\right)$ is a history of length $t$. A (pure) strategy $\sigma_{i j}$ for player $i$ of group $j$, for all $i=1,2, \ldots, n_{j}$ and for $j=A, B$, in $G^{\infty}(\delta)$, is a sequence of mappings $\left\{\sigma_{i j}^{t}\right\}_{t=0}^{\infty}$, where $\sigma_{i j}^{t}$ maps the collection of possible period- $t$ histories into an individual contribution $e_{i j}^{t} \in \Re_{+}$for player $i$ of group $j$ in period $t . \sigma_{i j}^{0}$ is thus the initial action of player $i$ of group $j$.

Let $\sigma_{j}=\left(\sigma_{1 j}, \ldots, \sigma_{n_{j} j}\right)$ for $j=A, B$, be the strategy profile of group $j$ members. Any strategy profile $\sigma=\left(\sigma_{A}, \sigma_{B}\right)$ generates the path of aggregate contributions $\left\{E_{A}^{t}(\sigma), E_{B}^{t}(\sigma)\right\}_{t=0}^{\infty}$ in the usual fashion: $\left(E_{A}^{0}(\sigma), E_{B}^{0}(\sigma)\right)=\sigma^{0}$ and for all $t>1,\left(E_{A}^{t}(\sigma), E_{B}^{t}(\sigma)\right)=\sigma^{t}\left(\left(E_{A}^{0}(\sigma), E_{B}^{0}(\sigma)\right), \ldots,\left(E_{A}^{t-1}(\sigma), E_{B}^{t-1}(\sigma)\right)\right)$. In period $t$, the induced action profiles $\left(E_{A}^{t}(\sigma), E_{B}^{t}(\sigma)\right)$ yield a payoff of $\pi_{i j}^{t}$ to player $i$ of group $j$. An outcome path $\left\{E_{A}^{t}(\sigma), E_{B}^{t}(\sigma)\right\}_{t=0}^{\infty}$ thus implies an infinite stream of stage-game payoffs $\left\{\pi_{i j}\left(E_{A}^{t}(\sigma), E_{B}^{t}(\sigma)\right)\right\}_{t=0}^{\infty}$ for player $i$ of group $j$. The discounted payoff to player $i$ of group $j$ from the infinite sequence of stage-game payoffs $\left\{\pi_{i j}^{t}\right\}_{t=0}^{\infty}$ is $\sum_{t=0}^{\infty} \delta^{t} \pi_{i j}^{t}$, so that her payoff in $G^{\infty}(\delta)$ obtained with the strategy profile $\sigma$ is given by

$$
\pi_{i j}^{\delta}(\sigma)=\sum_{t=0}^{\infty} \delta^{t} \pi_{i j}\left(E_{A}^{t}(\sigma), E_{B}^{t}(\sigma)\right)
$$

A strategy profile $\sigma$ is a Nash equilibrium in $G^{\infty}(\delta)$ if (i) for $i=1, \ldots, n_{A}, \sigma_{i A}$ is a best response to $\sigma_{A \backslash i}=\left(\sigma_{1 A}, \ldots, \sigma_{i-1 A}, \sigma_{i+1 A}, \ldots, \sigma_{n_{j} A}\right)$ and to $\sigma_{B}$; (ii) for $i=1, \ldots, n_{B}, \sigma_{i B}$ is a best response to $\sigma_{B \backslash i}=$ $\left(\sigma_{i B}, \ldots, \sigma_{i-1 B}, \sigma_{i+1 B}, \ldots, \sigma_{n_{j} B}\right)$ and to $\sigma_{A}$. A strategy profile $\sigma$ is a subgame perfect equilibrium in $G^{\infty}(\delta)$ if $\sigma$ induces a Nash equilibrium in the subgame following any history. We restrict attention to stationary subgame perfect equilibria (SSPE), i.e., equilibria in which, after any history, a stationary profile of actions is played thereafter.

\subsection{Friedman's Trigger Strategies}

In this section, we consider that the members of group $j,(j=A, B)$, use Friedman's Trigger Strategies (FTSs) in order to support cooperative behavior within their respective groups. FTSs prescribe that any deviation from the cooperative path in group $j$ is met with permanent reversion to the one-period symmetric non-cooperative equilibrium within group $j$ (Friedman 1971). Hence, with FTSs, group $j$ players' strategies only depend on the history of play of the group they belong to. However, group members' payoffs in a given group are contingent on the behavior of the members of the rival group. Therefore, we first consider that the members of the rival group $k \neq j$ have a fixed behavior over time - either full cooperation or noncooperation - before characterizing the conditions under which within-group cooperation can be supported as a SSPE within the two groups. It is worth pointing out that, even though the members of group $k$ have a fixed behavior, the collective action of group $k$ is a best response to that of the first group (i.e. group 
$j \neq k)$ in every period.

FTSs can be expressed as, for all $i=1,2, \ldots, n_{j}$,

$\sigma_{i j}^{0}=\widetilde{\widetilde{e}}_{j}\left(\widetilde{e}_{j}\right)$ if group $k$ members play $C(N C)$;

$\sigma_{i j}^{t}=\widetilde{\widetilde{e}}_{j}\left(\widetilde{e}_{j}\right)$ if $E_{j}^{\tau}=\widetilde{\widetilde{E}}_{j}, \quad \tau=0, \ldots, t-1 \quad t=1,2, \ldots .$, and if group $k$ members play $C(N C)$

$\sigma_{i j}^{t}=e_{j}^{*}\left(e_{j}^{* *}\right)$ if $E_{j}^{t-1} \neq \widetilde{E}_{j}$ and if group $k$ members play $C(N C)$

where 'group $k$ members play $C(N C)$ ' means that the members of the rival group Cooperate (do Not Cooperate) with each other.

We first establish the following Lemma.

Lemma 2 : In any period in which all group $j$ members contribute the joint-maximizing level of effort $\widetilde{\widetilde{e}}_{j}\left(\widetilde{e}_{j}\right)$, each member's best possible deviation from FTSs is to cut her contribution to 0 when there is perpetual cooperation (non-cooperation) within group $k \neq j$ for any $n_{j} \geq 2\left(n_{j} \geq 3\right)$.

Suppose first that there is perpetual cooperation within group $k$. In this case, the optimal deviation payoff for a member of group $j \neq k$ is $\pi_{j}^{d}\left(\widetilde{\widetilde{E}}_{j \backslash i}, \widetilde{\widetilde{E}}_{k}\right)=p_{j}\left(\widetilde{\widetilde{E}}_{j \backslash i}, \widetilde{\widetilde{E}}_{k}\right)\left(Y / n_{j}\right)$ where $p_{j}\left(\widetilde{\widetilde{E}}_{j \backslash i}, \widetilde{\widetilde{E}}_{k}\right)=$ $\left[\left(n_{j}-1\right) \widetilde{\widetilde{e}}_{j}\right] /\left[\left(n_{j}-1\right) \widetilde{\widetilde{e}}_{j}+n_{k} \widetilde{\widetilde{e}}_{k}\right]$ for $j \neq k$. Using (9), we then have

$$
\pi_{j}^{d}\left(\widetilde{\widetilde{E}}_{j \backslash i}, \widetilde{\widetilde{E}}_{k}\right)=p_{j}\left(\widetilde{\widetilde{E}}_{j \backslash i}, \widetilde{\widetilde{E}}_{k}\right) \frac{Y}{n_{j}}=\frac{n_{j}-1}{2 n_{j}-1} \frac{Y}{n_{j}}
$$

Observe that $p_{j}\left(\widetilde{\widetilde{E}}_{j \backslash i}, \widetilde{\widetilde{E}}_{k}\right)$ increases and approaches $p_{j}\left(\widetilde{\widetilde{E}}_{j}, \widetilde{\widetilde{E}}_{k}\right)=1 / 2$ as $n_{j}$ rises.

Suppose now that there is perpetual non-cooperation within group $k$. In this case, the optimal deviation payoff for a member of group $j \neq k$ is $\pi_{j}^{d}\left(\widetilde{E}_{j \backslash i}, E_{k}^{*}\right)=p_{j}\left(\widetilde{E}_{j \backslash i}, E_{k}^{*}\right)\left(Y / n_{j}\right)$ where $p_{j}\left(\widetilde{E}_{j \backslash i}, E_{k}^{*}\right)=$ $\left[\left(n_{j}-1\right) \widetilde{e}_{j}\right] /\left[\left(n_{j}-1\right) \widetilde{e}_{j}+n_{k} e_{k}^{*}\right]$ for $j \neq k$. Using (13) and (14), we then have

$$
\pi_{j}^{d}\left(\widetilde{E}_{j \backslash i}, E_{k}^{*}\right)=p_{j}\left(\widetilde{E}_{j \backslash i}, E_{k}^{*}\right) \frac{Y}{n_{j}}=\frac{n_{k}\left(n_{j}-1\right)}{n_{k}\left(n_{j}-1\right)+n_{j}} \frac{Y}{n_{j}}, \quad j \neq k .
$$

Observe that $p_{j}\left(\widetilde{E}_{j \backslash i}, E_{k}^{*}\right)$ increases and approaches $p_{j}\left(\widetilde{E}_{j}, E_{k}^{*}\right)$ (given by $\left.(15)\right)$ as $n_{j}$ rises. Furthermore, $p_{j}\left(\widetilde{E}_{j \backslash i}, E_{k}^{*}\right)$ is increasing in the size of the non-cooperative rival group.

FTSs are subgame perfect equilibrium strategies of the infinitely repeated game if and only if a singleperiod deviation from the strategy (and sticking to it subsequently) after any history, is not profitable for any member of group $j$. Suppose first that no single deviation has taken place in the previous periods. FTSs then prescribe that all members of group $j$ cooperate. As long as all players follow this prescription, a member of group $j$ collects, in each period, a payoff of $\pi_{j}\left(\widetilde{\widetilde{E}}_{j}, \widetilde{\widetilde{E}}_{k}\right)$ given by $(10)\left(\pi_{j}\left(\widetilde{E}_{j}, E_{k}^{*}\right)\right.$ given by (16)) when there is cooperation (non-cooperation) within the rival group. In contrast, suppose a member 
of group $j$ (optimally) deviates from FTSs in period $t$. She then obtains, in that period, a payoff of $\pi_{j}^{d}\left(\widetilde{\widetilde{E}}_{j \backslash i}, \widetilde{\widetilde{E}}_{k}\right)$ given by $(20)\left(\pi_{j}^{d}\left(\widetilde{E}_{j \backslash i}, E_{k}^{*}\right)\right.$ given by $\left.(21)\right)$ when there is cooperation (non-cooperation) within group $k$. FTSs prescribes that in the subsequent periods, the members of group $j$ do not cooperate and so, from period $t+1$ onwards, each member of group $j$ collects a payoff of $\pi_{j}\left(E_{j}^{*}, \widetilde{E}_{k}\right)$ given by (17) $\left(\pi_{j}\left(E_{j}^{* *}, E_{k}^{* *}\right)\right.$ given by $\left.(7)\right)$ when there is cooperation (non-cooperation) within group $k$. Hence, no member of group $j$ has an incentive to deviate from cooperation if and only if

$$
\frac{1}{1-\delta} \pi_{j}\left(\widetilde{\widetilde{E}}_{j}, \widetilde{\widetilde{E}}_{k}\right) \geq \pi_{j}^{d}\left(\widetilde{\widetilde{E}}_{j \backslash i}, \widetilde{\widetilde{E}}_{k}\right)+\frac{\delta}{1-\delta} \pi_{j}\left(E_{j}^{*}, \widetilde{E}_{k}\right)
$$

when there is cooperation within group $k$.

The corresponding condition when there non-cooperation within group $k$ is

$$
\frac{1}{1-\delta} \pi_{j}\left(\widetilde{E}_{j}, E_{k}^{*}\right) \geq \pi_{j}^{d}\left(\widetilde{E}_{j \backslash i}, E_{k}^{*}\right)+\frac{\delta}{1-\delta} \pi_{j}\left(E_{j}^{* *}, E_{k}^{* *}\right)
$$

Focusing on situations where self-enforcement is a binding constraint on the abilities of the members of group $j$ to cooperate, the critical value of the discount parameter above which cooperation can be sustained within group $j$, for $j=A, B$, is

$$
\delta_{j}^{C}=\frac{\pi_{j}^{d}\left(\widetilde{\widetilde{E}}_{j \backslash i}, \widetilde{\widetilde{E}}_{k}\right)-\pi_{j}\left(\widetilde{\widetilde{E}}_{j}, \widetilde{\widetilde{E}}_{k}\right)}{\pi_{j}^{d}\left(\widetilde{\widetilde{E}}_{j \backslash i}, \widetilde{\widetilde{E}}_{k}\right)-\pi_{j}\left(E_{j}^{*}, \widetilde{E}_{k}\right)}, \quad j \neq k .
$$

when there is Cooperation within the rival group, and

$$
\delta_{j}^{N}=\frac{\pi_{j}^{d}\left(\widetilde{E}_{j \backslash i}, E_{k}^{*}\right)-\pi_{j}\left(\widetilde{E}_{j}, E_{k}^{*}\right)}{\pi_{j}^{d}\left(\widetilde{E}_{j \backslash i}, E_{k}^{*}\right)-\pi_{j}\left(E_{j}^{* *}, E_{k}^{* *}\right)}, \quad j \neq k .
$$

when there is Non-cooperation within the rival group.

Substitute (10), (17) and (20) into (24) to get

$$
\delta_{j}^{C}\left(n_{j}\right)=\frac{\left(2 n_{j}-3\right)\left(n_{j}+1\right)^{2}}{4\left[n_{j}^{2}\left(n_{j}-1\right)-1\right]} .
$$

Observe that $\delta_{j}^{C}\left(n_{j}\right)$ is independent of $n_{k}$ as the other group acts as a single entity.

Substitute (7), (16) and (21) into (25) to get

$$
\delta_{j}^{N}\left(n_{j}, n_{k}\right)=\frac{\left(n_{j}+n_{k}\right)^{2}\left[n_{k}\left(n_{j}-2\right)+\left(n_{j}-1\right)\right]}{\left(n_{k}+1\right)^{2}\left[n_{j}\left(n_{j}+n_{k}\right)\left(n_{j}-2\right)+n_{k}\left(n_{j}-1\right)+n_{j}\right]}, \quad j \neq k .
$$

We now study how the ability of group $j$ to maintain a cooperative outcome is affected by an increase in its size. Ease of cooperation in group $j$, as measured by $\delta_{j}^{C}\left(n_{j}\right)$ or $\delta_{j}^{N}\left(n_{j}, n_{k}\right)$, depends on how payoffs under defection, cooperation and non-cooperation evolve as the group grows larger. This in turn commands the incentive to cheat, the benefit from cooperation and the penalty for cheating. Observe first that an increase 
in size diminishes the per-capita value of the prize and that this affects equally the different payoffs. Indeed, one can see that the individual payoffs, under cooperation (given by (10) and (16)), non-cooperation (given by (17) and (7)) and defection (given by (20) and (21)), when there is respectively cooperation or noncooperation within the rival group, are the product of two terms, one being the per-capita value of the total rent, i.e., $Y / n_{j}$. We can then evaluate the impact of an increase in $n_{j}$ on $\delta_{j}^{C}\left(n_{j}\right)$ and $\delta_{j}^{N}\left(n_{j}, n_{k}\right)$ in terms of group $j$ 's payoff (given by multiplying individual payoff by group size).

There are several effects. First, an increase in $n_{j}$ does not affect group $j$ 's payoff under cooperation, as one can see from (10) and (16). This is because the share of the rent received by group $j$, under cooperation, is either equal to $1 / 2$ or only depends on the size of the other group (when its members do not cooperate as shown by (15)). Second, the severity of the penalty for cheating is increasing in $n_{j}$ because the larger the size of group $j$ is, the more pervasive the free-rider problem and the lower the relative effectiveness of that group both when there is cooperation and non-cooperation within group $k \neq j .^{7}$ This effect causes $\delta_{j}^{C}\left(n_{j}\right)$ and $\delta_{j}^{N}\left(n_{j}, n_{k}\right)$ to be decreasing in $n_{j}$. The remaining effect is that the temptation to cheat rises with an increase in group size because group $j$ 's share of the rent under defection is growing closer to group $j$ 's share of the rent under cooperation with an increase in $n_{j}$, both when there is cooperation and non-cooperation within group $k \neq j$, as one can observe from (20) and (21). ${ }^{8}$ This last effect causes $\delta_{j}^{C}\left(n_{j}\right)$ and $\delta_{j}^{N}\left(n_{j}, n_{k}\right)$ to be increasing in $n_{j}$. Hence, an increase in membership has conflicting effects on the ability of a given group to support cooperative behavior in Nash reversion strategies, a point already stressed by Pecorino (1998) in a different context.

The impact of an increase in $n_{k}$ on $\delta_{j}^{N}\left(n_{j}, n_{k}\right)$ (for $j \neq k$ ) also involves several effects. First, the penalty for cheating becomes less severe because of the increased free-rider problem within the rival group as a result of its larger size. ${ }^{9}$ Second, the temptation to cheat rises with $n_{k}$ because group $j$ 's share of the rent under defection is increasing in $n_{k}$, as one can see from (21). These two effects cause $\delta_{j}^{N}\left(n_{j}, n_{k}\right)$ to be increasing in $n_{k}$. However, the benefits from cooperation for group $j$ are increasing in the size of group $k \neq j$ because, again, the larger the size of the rival group is, the greater its collective action problem and the higher the relative effectiveness of group $j$. This last effect causes $\delta_{j}^{N}\left(n_{j}, n_{k}\right)$ to be decreasing in $n_{k}$. Hence, an increase in size of the non-cooperative rival group has also conflicting effects on the ability of a

\footnotetext{
${ }^{7}$ Let $\Pi_{j}()=.n_{j} \pi_{j}($.$) denote the aggregate payoff of group j$. From (7) and (17), one can easily verify that $\Pi_{j}\left(E_{j}^{* *}, E_{k}^{* *}\right)$ and $\Pi_{j}\left(E_{j}^{*}, \widetilde{E}_{k}\right)$ - i.e., the payoff of group $j$ under non-cooperation when there is respectively non-cooperation and cooperation within group $k \neq j$ - are indeed both decreasing in $n_{j}$.

${ }^{8}$ It follows that the deviator's payoff multiplied by group size - which actually does not correspond, in this case, to group $j$ 's payoff because the deviator has not the same payoff than non-deviators - is increasing in $n_{j}$.

${ }^{9}$ Under non-cooperation within the two groups, $\Pi_{j}\left(E_{j}^{* *}, E_{k}^{* *}\right)$ is indeed increasing in $n_{k}$ for $k \neq j$.
} 
given group to sustain within-group cooperation.

However, Lemma 3 shows that there are monotonicity results for the overall effect of $n_{j}$ on $\delta_{j}^{C}\left(n_{j}\right)$ and on $\delta_{j}^{N}\left(n_{j}, n_{k}\right)$ as well as for the overall effect of $n_{k}$ on $\delta_{j}^{N}\left(n_{j}, n_{k}\right)($ for $j \neq k)$ :

Lemma 3: If $n_{j} \geq 4($ for $j=A, B)$, then : (i) $\frac{d \delta_{j}^{C}\left(n_{j}\right)}{d n_{j}}<0$ and $\frac{\partial \delta_{j}^{N}\left(n_{j}, n_{k}\right)}{\partial n_{j}}<0$ for $j=A, B$; (ii) $\frac{\partial \delta_{j}^{N}\left(n_{j}, n_{k}\right)}{\partial n_{k}}<0$ for $j=A, B$ and $j \neq k$.

The explanation of these results is the following. The contribution of our analysis is the study of collective action in the presence of competing groups. In that context, the penalty for cheating is much larger than without competition between groups. Indeed, when there is reversion to the non-cooperative outcome within a group, the free-rider problem within that group is exploited by the competing group which responds by increasing its rent-seeking effort so as to extract a larger share of the rent to the detriment of the first group. Hence, the severity of the penalty for cheating associated with defection increases more rapidly than the temptation to cheat as group size rises. In turn, cooperation is less difficult to maintain as the number of fellow members rises both when there is cooperation and non-cooperation within the rival group. Cooperation in group $j$ is also less difficult to maintain as the size of the non-cooperative rival group rises. As discussed above, when the rival group grows larger, defection is more tempting and the penalty for cheating also becomes less severe. But, there is much to be gained from cooperation because the group's share of the rent approaches 1 as the rival group grows larger (as shown by (15)) as a result of its increased collective action problem.

We now hold constant the size of each group and we determine whether home group cooperation is more likely when facing a cooperative or non-cooperative rival group. We have:

Lemma 4: If $n_{j} \geq 4($ for $j=A, B)$, then $\delta_{j}^{C}\left(n_{j}\right)>\delta_{j}^{N}\left(n_{j}, n_{k}\right)$ for $j=A, B$.

In other words, cooperation can be more easily sustained when facing a non-cooperative rival group which confirms the presumption that a weaker rival group reinforces the cohesion and strength of the competing group. In fact, cooperation and non-cooperation within the rival group have opposite effects on the ability to maintain cooperation within a given group. First, the Nash-punishment is less severe when facing a noncooperative rival group because, in that situation, both groups suffer from the collective action problem. This would require a higher discount factor to sustain within-group cooperation. Another effect, however, is that the gains from cooperation are much larger when facing a non-cooperative rival group and, hence, a lower discount factor may be sufficient to sustain within-group cooperation. Finally, the cooperative level of individual effort is lower with a non-cooperative rival group. This causes a lower incentive to cheat and, hence, a lower critical discount factor to sustain cooperation in this case. According to Lemma 4, it turns 
out that a lower incentive to cheat and higher relative benefits of cooperation dominate the lower penalty of cheating when there is non-cooperation compared to cooperation within the rival group. Intuitively, as discussed above, the benefits from cooperation are much higher with a non-cooperative rival group.

Finally, Lemma 5 ranks the different values of the critical discount factor.

Lemma 5: If $n_{j} \geq 4($ for $j=A, B)$ and $n_{A} \geq n_{B}$, then

$$
0<\delta_{B}^{N}\left(n_{A}, n_{B}\right) \leq \delta_{A}^{N}\left(n_{A}, n_{B}\right)<\delta_{A}^{C}\left(n_{A}\right) \leq \delta_{B}^{C}\left(n_{B}\right)<1
$$

The inequality $\delta_{A}^{C}\left(n_{A}\right) \leq \delta_{B}^{C}\left(n_{B}\right)$ directly follows from (i) of Lemma 3 . If there is cooperation within the two groups, each group gets half of the total rent in equilibrium. But, when there is perpetual cooperation within the rival group, the larger group has a lower share of the rent than the smaller group if fellow members behave non-cooperatively. Hence, the punishment being harsher, cooperation is less difficult to sustain in group $A$ even though defection is more tempting in this group. When there is however perpetual non-cooperation within the rival group, cooperation is more difficult to sustain in the larger group than in the smaller group. Indeed, while the Nash punishment is less severe for the smaller group, the gains from cooperation are also much higher. This is because the share allocated to the cooperative group is increasing in the size of the non-cooperative rival group. Furthermore, defection is less attractive for the smaller group and then $\delta_{B}^{N}\left(n_{A}, n_{B}\right) \leq \delta_{A}^{N}\left(n_{A}, n_{B}\right)$.

Throughout the rest of the paper, we shall assume that $n_{j} \geq 4$ for $j=A, B$ and that $n_{A} \geq n_{B}$ so that all the Lemmata formulated above remain valid. We are now ready to state the following result:

Proposition 1: Assume that all group members adopt FTSs given by (19). Then perpetual cooperation can be sustained within the two groups as a SSPE if and only if $\delta \geq \delta_{B}^{C}\left(n_{B}\right)$.

From (28), $\delta \geq \delta_{B}^{C}\left(n_{B}\right)$ implies that $\delta>\delta_{A}^{C}\left(n_{A}\right)$. Hence, for any $\delta \geq \delta_{B}^{C}\left(n_{B}\right)$, no individual in both groups has an incentive to deviate from the cooperative path in her group. If a deviation has taken place within group $k$ in the previous periods, the members of group $j \neq k$ still have an incentive to continue cooperating because, by Lemma $5, \delta \geq \delta_{B}^{C}\left(n_{B}\right)$ implies that $\delta>\delta_{j}^{N}\left(n_{A}, n_{B}\right)$ for $j=A, B$. It follows that for any $\delta \in\left(\delta_{B}^{C}\left(n_{B}\right), 1\right)$, perpetual cooperation within each of the two groups can be sustained as a SSPE provided any deviations within a given group are followed by this group reverting to the one-shot symmetric non-cooperative outcome. In that situation, the two groups neutralize each other in the contest and each group obtains half of the total rent in every period.

If however $\delta<\delta_{B}^{C}\left(n_{B}\right)$, then perpetual cooperation cannot be sustained as a SSPE using FTSs within each of the two groups independently of whether the members of the rival group act cooperatively or noncooperatively. In particular, it is interesting to note that, for any $\delta \in\left(\delta_{A}^{C}\left(n_{A}\right), \delta_{B}^{C}\left(n_{B}\right)\right)$, each member 
of the smaller group (i.e., group $B$ ) but no member of the larger group (i.e., group $A$ ) has a profitable deviation from FTSs in every subgame in which all members of each group cooperated with their fellow members in all previous periods. Again, when facing a cooperative group, cooperation can be more easily sustained in the larger group because reversion to non-cooperation is more costly for this group due to the greater free-riding incentives.

More generally, for any $\delta<\delta_{B}^{C}\left(n_{B}\right)$ and still restricting attention to FTSs, we would need to assume that the members of group $j$ only use FTSs to sustain within-group cooperation while the members of group $k \neq j$ never cooperate with each other. Clearly, in that situation, cooperation can be sustained as a SSPE using FTSs within group $j$ if and only if $\delta \geq \delta_{j}^{N}\left(n_{A}, n_{B}\right)$.

\subsection{Double-Edge Trigger Strategies}

We now focus on situations where cooperative behavior can be supported as a SSPE within only one group. With FTSs, cheating on the agreement in the cooperative group is deterred by the threat of reverting to the non-cooperative equilibrium for the rest of time, once cheating has been detected. In any case, the members of the rival group behave non-cooperatively and play their best response to the actions of their fellow group members as well as to the collective action of the first group. However, from Lemma 1, reversion to the non-cooperative equilibrium in the first group makes cooperation more profitable for any member of the rival group. For this reason, it is only natural to investigate whether the members of the rival group can support, in their turn, cooperative behavior through the threat of reverting back to the non-cooperative equilibrium. If it is the case, then defection in the first group triggers both permanent reversion to the within-group non-cooperative outcome and permanent cooperation within the rival group. This would in turn enhance the incentives to cooperate in the first group. To account for this double edge threat to the cooperative group, we thus introduce Double-Edge Trigger Strategies (DETSs) which constitute, we believe, a plausible explanation for the stability of within-group cooperation in the intergroup competition.

More formally, the strategy for player $i$ in group $j$, for all $i=1,2, \ldots, n_{j}$, who takes a decision in period $t$, is

$$
\begin{aligned}
& \sigma_{i j}^{0}=\widetilde{e}_{j} ; \\
& \sigma_{i j}^{t}=\widetilde{e}_{j} \text { if }\left(E_{j}^{\tau}, E_{k}^{\tau}\right)=\left(\widetilde{E}_{j}, E_{k}^{*}\right), \quad j \neq k, \quad \tau=0, \ldots, t-1, \quad t=1,2, \ldots ; \\
& \sigma_{i j}^{t}=e_{j}^{*} \text { if } E_{j}^{t-1} \neq \widetilde{E}_{j}, \quad j \neq k \text { and } E_{k}^{\tau}=E_{k}^{*}, \quad \tau=0, \ldots, t-1 ; \\
& \sigma_{i j}^{t}=e_{j}^{*} \text { if there exists } t^{\prime}, \text { with } 2 \leq t^{\prime}<t, \text { such that }\left(E_{j}^{\tau}, E_{k}^{\tau}\right)=\left(E_{j}^{*}, \widetilde{E}_{k}\right), \quad j \neq k \\
& \tau=t^{\prime}, \ldots, t-1, \quad t=t^{\prime}+1, t^{\prime}+2 \ldots ; \\
& \sigma_{i j}^{t}=e_{j}^{* *} \text { otherwise }
\end{aligned}
$$


and the strategy for player $i$ in group $k \neq j$, for all $i=1,2, \ldots, n_{k}$, who takes a decision in period $t$, is

$$
\begin{aligned}
\sigma_{i k}^{0} & =e_{k}^{*} ; \\
\sigma_{i k}^{t} & =e_{k}^{*} \text { if }\left(E_{j}^{\tau}, E_{k}^{\tau}\right)=\left(\widetilde{E}_{j}, E_{k}^{*}\right), \quad j \neq k, \quad \tau=0, \ldots, t-1, \quad t=1,2, \ldots ; \\
\sigma_{i k}^{t}= & \widetilde{e}_{k} \text { if } E_{j}^{t-1} \neq \widetilde{E}_{j}, \quad j \neq k \text { and } E_{k}^{\tau}=E_{k}^{*}, \quad \tau=0, \ldots, t-1 ; \\
\sigma_{i k}^{t}= & \widetilde{e}_{k} \text { if there exists } t^{\prime}, \text { with } 2 \leq t^{\prime}<t, \text { such that }\left(E_{j}^{\tau}, E_{k}^{\tau}\right)=\left(E_{j}^{*}, \widetilde{E}_{k}\right), \quad j \neq k \\
& \tau=t^{\prime}, \ldots, t-1, \quad t=t^{\prime}+1, t^{\prime}+2 \ldots ; \\
\sigma_{i k}^{t}= & e_{k}^{* *}, \quad \text { otherwise. }
\end{aligned}
$$

In words, in the first period - the first line of (29) and (30) - each individual in group $j$ cooperates and contributes the joint-welfare maximizing level of effort $\widetilde{e}_{j}$, given by (13), while the members of group $k \neq j$ do not cooperate and then contribute $e_{k}^{*}$, given by (14). In any period $t>0$ - the second line of (29) and $(30)$ - the members of group $j$ will continue to cooperate and to contribute $\widetilde{e}_{j}$ while the members of group $k$ will continue to behave non-cooperatively and to contribute $e_{k}^{*}$ as long as group $j$ members have cooperated in the past. If a member of group $j$ deviated in period $t-1$ - the third line of $(29)$ and (30) -, then in period $t$ all members of group $j$ revert to the non-cooperative level of effort $e_{j}^{*}$ and all members of group $k \neq j$ are called to start to cooperate with each other and to contribute the joint-welfare maximizing level of effort $\widetilde{e}_{k}$. In any period $t>2$ - the fourth line of (29) and (30) -, group $j$ members will not cooperate while group $k$ members will continue to cooperate if there exists $t^{\prime}$, with $2 \leq t^{\prime}<t$, such that from period $t^{\prime}$ until period $t-1$, all group $k$ members have cooperated while group $j$ members have not cooperated. The third and fourth lines of (29) and (30) then mean that, following a deviation from the cooperative phase within group $j$, the game enters a new phase with cooperation within group $k$ and non-cooperation within group $j$. This phase lasts until a member of group $k \neq j$ also deviates from the cooperative level of effort. In this case - the fifth line of (29) and (30) - all members of group $k$ revert back to the non-cooperative outcome and contribute the non-cooperative level of effort, so that the members of the two groups are stuck at the one-shot non-cooperative equilibrium and contribute $e_{j}^{* *}$ and $e_{k}^{* *}$ given by (5). Observe that DETSs allow for within-group cooperation after a phase of non-cooperation but only if group members never cooperated before.

DETSs are subgame perfect equilibrium strategies of the infinitely repeated game if and only if a singleperiod deviation from the strategy (and sticking to it subsequently) after any history, is not profitable for any member of either group. Suppose first that no single deviation has taken place in the previous periods. DETSs then prescribe that all members of group $j$ cooperate while the members of group $k \neq j$ do not cooperate. As long as all players follow this prescription, each member of group $j$ collects a payoff of 
$\pi_{j}\left(\widetilde{E}_{j}, E_{k}^{*}\right)$ given by (16) in each period. In contrast, suppose a member of group $j$ (optimally) deviates from DETSs in period $t$. She then obtains, in that period, a payoff of $\pi_{i j}^{d}\left(\widetilde{E}_{j \backslash i}, E_{k}^{*}\right)$ given by (21). DETSs prescribe that, in the subsequent periods, the members of group $j$ do not cooperate while the member of group $k \neq j$ cooperate with each other. Hence, from period $t+1$ onwards, each member of group $j$ collects a payoff of $\pi_{j}\left(E_{j}^{*}, \widetilde{E}_{k}\right)$ given by (17). It follows that no member of group $j$ has an incentive to deviate from within-group cooperation if

$$
\frac{1}{1-\delta} \pi_{j}\left(\widetilde{E}_{j}, E_{k}^{*}\right) \geq \pi_{j}^{d}\left(\widetilde{E}_{j \backslash i}, E_{k}^{*}\right)+\frac{\delta}{1-\delta} \pi_{j}\left(E_{j}^{*}, \widetilde{E}_{k}\right), \quad j \neq k
$$

Focusing on situations where self-enforcement is a binding constraint, the critical value of the discount parameter is

$$
\delta_{j}^{N C}\left(n_{j}, n_{k}\right)=\frac{\pi_{j}^{d}\left(\widetilde{E}_{j \backslash i}, E_{k}^{*}\right)-\pi_{j}\left(\widetilde{E}_{j}, E_{k}^{*}\right)}{\pi_{j}^{d}\left(\widetilde{E}_{j \backslash i}, E_{k}^{*}\right)-\pi_{j}\left(E_{j}^{*}, \widetilde{E}_{k}\right)}, \quad j \neq k
$$

where the $N C$ superscript indicates that $N$ on-cooperation is followed by Cooperation in the other group in case of a deviation within group $j$. Clearly, because cooperation of the others is always detrimental to the members of a given group (Lemma 1$), \delta_{j}^{N C}\left(n_{j}, n_{k}\right)$ is lower than $\delta_{j}^{N}\left(n_{j}, n_{k}\right)$, for $j=A, B$, which was calculated assuming perpetual non-cooperation within the rival group.

To ensure subgame perfection, we must also verify that no player of group $k \neq j$ has an incentive to deviate from cooperation along the out-of-equilibrium path following a deviation within group $j$. From the analysis of the previous section, we know that, when there is non-cooperation within group $j$, it is not profitable for any member of group $k \neq j$ to deviate from cooperation (provided any deviation is met with permanent reversion to the one-shot symmetric Nash equilibrium) as long as $\delta \geq \delta_{k}^{N}\left(n_{j}, n_{k}\right)$ for $k \neq j$. Therefore, cooperation within group $j$ (and non-cooperation within group $k \neq j$ ) can be sustained as a SSPE using DETSs if and only if

$$
\delta \geq \max \left\{\delta_{j}^{N C}\left(n_{j}, n_{k}\right), \delta_{k}^{N}\left(n_{j}, n_{k}\right)\right\}, \quad j \neq k .
$$

Suppose first that the members of the smaller group, i.e. group $B$, start by cooperating and follow the strategy described in (29) while the members of the larger group, i.e. group $A$, start by not cooperating and follow the strategy described in (30). Since DETSs involve harsher punishments than FTSs, we have that $\delta_{B}^{N C}\left(n_{A}, n_{B}\right)<\delta_{B}^{N}\left(n_{A}, n_{B}\right)$. From (28), we also have that $\delta_{A}^{N}\left(n_{A}, n_{B}\right) \geq \delta_{B}^{N}\left(n_{A}, n_{B}\right)$. This implies that $\delta_{B}^{N C}\left(n_{A}, n_{B}\right)<\delta_{A}^{N}\left(n_{A}, n_{B}\right)$, and so, from (33), the following Proposition holds.

Proposition 2: Suppose that group B members start by cooperating and adopt DETSs given by (29) and that group A members start by not cooperating and adopt DETSs given by (30). Then, cooperation only 
in the smaller group (i.e. group B) can be sustained as a SSPE if and only if $\delta \geq \delta_{A}^{N}\left(n_{A}, n_{B}\right)$.

$\delta_{B}^{N C}\left(n_{A}, n_{B}\right)$ is not relevant to the outcome of the game. Indeed, if cooperation can be maintained within group $A$ (following defection and reversion to the non-cooperative outcome within group $B$ ), it can also be maintained within group $B$ (when there is non-cooperation within group $A$ ) because $\delta_{A}^{N}\left(n_{A}, n_{B}\right)>\delta_{B}^{N}\left(n_{A}, n_{B}\right)$. Then, for any $\delta \geq \delta_{A}^{N}\left(n_{A}, n_{B}\right)$, each member of group $B$ finds it more profitable to pursue cooperation than to deviate while the members of group $A$ never cooperate. If however $\delta<\delta_{A}^{N}\left(n_{A}, n_{B}\right)$, then defection of one group $B$ member (triggering reversion to the non-cooperative outcome within that group) cannot credibly trigger perpetual cooperation within group $A$ and, therefore, DETSs do not satisfy the subgame perfection requirement. DETSs can then be compared to FTSs to yield the following Proposition.

Proposition 3: If $\delta<\delta_{A}^{N}\left(n_{A}, n_{B}\right)$, DETSs with cooperation only in the smaller group (i.e., group B) do not form a SSPE. However, if $\delta \geq \delta_{B}^{N}\left(n_{A}, n_{B}\right)$ (with $\left.\delta_{B}^{N}\left(n_{A}, n_{B}\right)<\delta_{A}^{N}\left(n_{A}, n_{B}\right)\right)$, cooperation can be sustained as a SSPE in the smaller group if its members adopt FTSs and face a non-cooperative group.

This result is somewhat counterintuitive. Because DETSs involve harsher punishments than FTSs, one would expect that DETSs would increase the range of discount factors for which cooperative behavior can be supported in the smaller group. This is not however the case because cooperative behavior is more difficult to support in the larger group than in the smaller group when facing a non-cooperative group (Lemma 5). Therefore, the threat of cooperation within the rival group is not effective in this case and DETSs are simply FTSs completed with an out-of-equilibrium "perfection" constraint that further restrains the range of discount factors for which cooperation can be supported as a SSPE in the smaller group.

We now analyze the symmetric situation where the members of the larger group, i.e. group $A$, start by cooperating and follow the strategy described in (29) while the members of the smaller group, i.e. group $B$, start by not cooperating and follow the strategy described in (30). Again, since DETSs involve harsher punishments than FTSs, we have that $\delta_{A}^{N C}\left(n_{A}, n_{B}\right)<\delta_{A}^{N}\left(n_{A}, n_{B}\right)$. From (28) we also have $\delta_{A}^{N}\left(n_{A}, n_{B}\right)>\delta_{B}^{N}\left(n_{A}, n_{B}\right)$. We then need to compare $\delta_{A}^{N C}\left(n_{A}, n_{B}\right)$ and $\delta_{B}^{N}\left(n_{A}, n_{B}\right)$ and determine which of these critical values is smaller and which is higher. Indeed, and in contrast with the symmetric case analyzed above, DETSs can potentially be used to support cooperative behavior in group $A$ for some discount parameters below $\delta_{A}^{N}\left(n_{A}, n_{B}\right)$ if cooperation within group $B$ can be supported when there is permanent reversion to the non-cooperative outcome within group $A$, i.e., if $\delta>\delta_{B}^{N}\left(n_{A}, n_{B}\right)$.

Substitute (16), (17) and (21) into (32) to get

$$
\delta_{A}^{N C}\left(n_{A}, n_{B}\right)=\frac{n_{B}\left(n_{A}+1\right)^{2}\left[n_{B}\left(n_{A}-2\right)+\left(n_{A}-1\right)\right]}{\left(n_{B}+1\right)^{2}\left[n_{A}^{2}\left(n_{A} n_{B}-1\right)-n_{B}\right]} .
$$


In contrast with $\delta_{A}^{N}\left(n_{A}, n_{B}\right)$, the derivative of $\delta_{A}^{N C}\left(n_{A}, n_{B}\right)$ with respect to $n_{A}$ remains indeterminate and we cannot rank unambiguously $\delta_{B}^{N}\left(n_{A}, n_{B}\right)$ and $\delta_{A}^{N C}\left(n_{A}, n_{B}\right)$. However, one can establish numerically that $\delta_{B}^{N}\left(n_{A}, n_{B}\right)>\delta_{A}^{N C}\left(n_{A}, n_{B}\right)$ as long as group size asymmetry is not too strong (see Table 1 where bold numbers represent a higher level of $\left.\delta_{A}^{N C}\left(n_{A}, n_{B}\right)\right) .{ }^{10}$

\begin{tabular}{ccccccc}
\hline & & $\lambda=1.5$ & $\lambda=2$ & $\lambda=5$ & $\lambda=10$ & $\lambda=100$ \\
\hline 4 & 0.126 & 0.100 & 0.069 & 0.016 & $\mathbf{- 0 . 0 0 1}$ & $\mathbf{- 0 . 0 1 6}$ \\
20 & 0.080 & 0.066 & 0.050 & 0.019 & 0.009 & $\mathbf{- 0 . 0 0 1}$ \\
\hline & 0.036 & 0.030 & 0.023 & 0.009 & 0.005 & 0.000 \\
\hline
\end{tabular}

Figure 1: The difference between $\delta_{B}^{N}\left(n_{A}, n_{N}\right)$ and $\delta_{A}^{N C}\left(n_{A}, n_{N}\right)$.

Again, from (33), DETSs are subgame perfect equilibrium strategies only if one agent's defection within group $A$ can credibly trigger cooperation within group $B$, hence only if $\delta \geq \delta_{B}^{N}\left(n_{A}, n_{B}\right)>\delta_{A}^{N C}\left(n_{A}, n_{B}\right)$. From (33), we then have the following Proposition.

Proposition 4: Suppose that group A members start by cooperating and adopt DETSs given by (29) and that group B members start by not cooperating and adopt DETSs given by (30). Then, cooperation only in the larger group, i.e. group $A$, can be sustained as a SSPE if and only if $\delta \geq \delta_{B}^{N}\left(n_{A}, n_{B}\right)$.

This shows the existence of a situation symmetric to the situation in Proposition 2, except that cooperation in the larger group can be sustained for a larger range of discount factors than cooperation in the smaller group through the use of DETSs. There is indeed a range of discount factors (i.e. $\left.\delta \in\left(\delta_{B}^{N}\left(n_{A}, n_{B}\right), \delta_{A}^{N}\left(n_{A}, n_{B}\right)\right)\right)$ for which every member of group $A$ has a profitable deviation from cooperation when there is perpetual non-cooperation in group $B$ while all members of group $B$ find it more profitable to enforce and to maintain cooperation in case of permanent reversion to the non-cooperative outcome within group $A$. In other words, the cooperation of the others constitutes a credible threat for the members of the larger group when they begin the infinitely repeated game by cooperating. This is not the case for the members of the smaller group.

In the previous subsection, we have shown that cooperation is generally easier within large groups. This is the case when we analyze the implications of increasing the size of a given group but also when making across-groups comparisons assuming perpetual cooperation within the rival group. There is one exception.

\footnotetext{
${ }^{10}$ In the limit i.e. when the larger group grows to infinity, we indeed have $\delta_{B}^{N}\left(n_{B}\right)-\delta_{A}^{N C}\left(n_{A}, n_{B}\right)<0$. We have $\lim _{n_{A} \rightarrow \infty} \delta_{A}^{N C}\left(n_{A}, n_{B}\right)=\frac{1}{1+n_{B}}$ on the one hand and (with the use of $\left.(27)\right) \lim _{n_{A} \rightarrow \infty} \delta_{B}^{N}\left(n_{A}, n_{B}\right)=\frac{n_{B}-2}{n_{B}\left(n_{B}-1\right)-1}$ on the other. The first limit is larger than the second one.
} 
Indeed, the smaller group can more easily sustain cooperation if we assume perpetual non-cooperation within the larger group. But, this greater ability of the smaller group, in this particular case, turns again to the advantage of the members of the larger group because the members of the larger group play on the expectation that a deviation might trigger perpetual cooperation within the smaller group.

Combining Propositions 3 and 4, we also see that for the same range of discount factors, cooperation can be sustained either in the smaller group through the use of FTSs or in the larger group through the use of DETSs. Hence, the larger group is at least as likely to maintain within-group cooperation as the smaller group, in which case it gets a larger share of the rent to the detriment of the smaller group.

Note, however, that when the size of the prize is constant, as it is the case in this paper, large groups are disadvantaged in terms of individual payoff. But it might well be possible that larger groups are more effective both in terms of aggregate levels of collective action and in terms of per-capita payoffs. In the context of this paper, when there is cooperation within the larger group and non-cooperation within the smaller group, individual pay-off is also higher in the larger group if group size asymmetry is not too strong. From (16) and (17), this is case if $\sqrt{n_{A}}<n_{B}$.

\section{Concluding remarks}

In this article, we develop an analysis of collective action that exhibits two central features. First, two groups of different size compete for an exogenous rent and, second, the members of each group can sustain within-group cooperation through the use of trigger strategies in a repeated game structure. While none of these features is new in the collective action literature, the innovation of this paper is in putting them together in a simple framework. We then show that increasing the size of one group (while that of the other group is kept unchanged) decreases the minimum value of the discount factor above which cooperation in this group is sustainable as a subgame perfect outcome. We also show that the set of parameters for which cooperation can be maintained within the larger group as a subgame perfect outcome is as large as that for which cooperation can be sustained in the smaller group. The crucial features driving our results is that Nash punishment is more severe for larger groups in a context of competing groups, and that the threat of cooperation within the rival group is a credible threat only for the members of the larger group.

The simplicity of the framework analyzed in this paper is attractive but might be criticized on several fronts. First, we have focused on equilibria such that full cooperation within one group or both can be sustained as a subgame perfect outcome. Alternatively, we could have considered, for a fixed value of the discount factor, the maximal level of effort that members in a group can achieve. It is, however, important to remember that in our analysis, the effectiveness of a group is determined not by its absolute efficiency but by its efficiency relative to that of the other group (through the intergroup competition); hence by its 
relative efficiency at circumventing free-riding. Therefore, as long as the extent of free-riding - as measured by the divergence between the non-cooperative level and the actual level of collective action - is increasing in group size, the qualitative results of our rent-seeking game should continue to hold. Second, we assumed that any deviation from the cooperative path is punished with Nash-reversion within the corresponding group (and possibly with cooperation within the rival group). A natural extension of the present analysis would be to consider two-phase punishment schemes à la Abreu (1986). With Abreu's stick-and-carrot strategies, the members of each group would conform to a "stick" phase - in which group members would contribute less than in the one-shot game - because of the "carrot" of a subsequent return to cooperation. We believe that the analysis of optimal punishment schemes in a setting such as ours is an interesting question for future research.

\section{Appendix}

\subsection{Proof of Lemma 1}

Given $n_{j} \geq 2, \pi_{j}\left(\widetilde{E}_{j}, E_{k}^{*}\right)$ given by (16) is equal to $\pi_{j}\left(\widetilde{\widetilde{E}}_{A}, \widetilde{\widetilde{E}}_{B}\right)$ given by (10) for $n_{k}=1$ and is increasing in $n_{k}$ for $n_{k}>1$. We then have $\pi_{j}\left(\widetilde{E}_{j}, E_{k}^{*}\right)>\pi_{j}\left(\widetilde{\widetilde{E}}_{A}, \widetilde{\widetilde{E}}_{B}\right)$ for any $n_{j} \geq 2$ and $n_{k} \geq 2$. Similarly, given $n_{k} \geq 2$, $\pi_{k}\left(E_{A}^{* *}, E_{B}^{* *}\right)$ given by $(7)$ is equal to $\pi_{k}\left(E_{k}^{*}, \widetilde{E}_{j}\right)$ given by (17) for $n_{j}=1$ and is increasing in $n_{j}$ for $n_{j}>1$. Hence, we have $\pi_{k}\left(E_{A}^{* *}, E_{B}^{* *}\right)>\pi_{k}\left(E_{k}^{*}, \widetilde{E}_{j}\right)$ for any $n_{k} \geq 2$ and $n_{j} \geq 2$.

\subsection{Proof of Lemma 2}

Suppose first that the members of group $j$ use FTSs to sustain cooperative behavior while there is permanent cooperation within group $k \neq j$. When a person of group $j$ defects from the cooperative agreement, the share allocated to group $j$ is

$$
p_{j}\left(\widetilde{\widetilde{E}}_{j \backslash i}, \widetilde{\widetilde{E}}_{k}\right)=\frac{\left(n_{j}-1\right) \widetilde{\widetilde{e}}_{j}+e_{i j}^{d}}{\left(n_{j}-1\right) \widetilde{\widetilde{e}}_{j}+e_{i j}^{d}+n_{k} \widetilde{\widetilde{e}}_{k}}, \quad j \neq k,
$$

where (from (9)) $\widetilde{\widetilde{e}}_{j}=Y / 4 n_{j}$ and $\widetilde{\widetilde{e}}_{k}=Y / 4 n_{k}$ are the cooperative level of individual effort within group $j$ and $k . e_{i j}^{d}$ is the expenditure level of the member who defects. This agent optimally chooses $e_{i j}^{d}$ to maximize $\pi_{j}^{d}\left(\widetilde{\widetilde{E}}_{j \backslash i}, \widetilde{\widetilde{E}}_{k}\right)=\left[p_{j}\left(\widetilde{\widetilde{E}}_{j \backslash i}, \widetilde{\widetilde{E}}_{k}\right) Y / n_{j}\right]-e_{i j}^{d}$. The first-order condition to this problem implies that

$$
\frac{4 n_{j} Y^{2}}{\left[\left(2 n_{j}-1\right) Y+4 n_{j} e_{i j}^{d}\right]^{2}}-1=0
$$

The left-hand term is decreasing in $e_{i j}^{d}$. The individual who defects will then cut her contribution to 0 if $\left.\frac{\partial \pi_{j}^{d}\left(\widetilde{\widetilde{E}}_{\backslash \backslash i}, \widetilde{\widetilde{E}}_{k}\right)}{\partial e_{i j}^{d}}\right|_{e_{i j}^{d}=0}<0$, i.e., if $4 n_{j}<\left(2 n_{j}-1\right)^{2}$ which is indeed verified for any $n_{j} \geq 2$. 
Suppose now that the members of group $j$ use FTSs to sustain cooperative behavior while there is permanent non-cooperation within group $k \neq j$. When a person of group $j$ defects from the cooperative agreement, the share allocated to group $j$ is

$$
p_{j}\left(\widetilde{E}_{j \backslash i}, E_{k}^{*}\right)=\frac{\left(n_{j}-1\right) \widetilde{e}_{j}+e_{i j}^{d}}{\left(n_{j}-1\right) \widetilde{e}_{j}+e_{i j}^{d}+n_{k} e_{k}^{*}} \quad j \neq k,
$$

where $\widetilde{e}_{j}=\left[n_{k} /\left(n_{k}+1\right)^{2}\right]\left(Y / n_{j}\right)$ (given by 13) and $e_{k}^{*}=\left[1 /\left(n_{k}+1\right)^{2}\right]\left(Y / n_{k}\right)$ (given by $\left.(14)\right)$ are respectively the cooperative level of individual effort in group $j$ and non-cooperative level of individual effort in group $k$. $e_{i j}^{d}$ is still the expenditure level of the member who defects. This agent optimally chooses $e_{i j}^{d}$ to maximize $\pi_{j}^{d}\left(\widetilde{E}_{j \backslash i}, E_{k}^{*}\right)=\left[p_{j}\left(\widetilde{E}_{j \backslash i}, E_{k}^{*}\right) Y / n_{j}\right]-e_{i j}^{d}$. The first-order condition to this problem implies that

$$
\frac{n_{j}\left(n_{k}+1\right)^{2} Y^{2}}{\left[\left(n_{j}-1\right) n_{k} Y+n_{j}\left(n_{k}+1\right)^{2} e_{i j}^{d}+n_{j} Y\right]^{2}}-1=0, \quad j \neq k .
$$

The left-hand term is decreasing in $e_{i j}^{d}$. The individual who defects will then cut her contribution to 0 if $\left.\frac{\partial \pi_{j}^{d}\left(\widetilde{E}_{j \backslash i}, E_{k}^{*}\right)}{\partial e_{i j}^{d}}\right|_{e_{i j}^{d}=0}<0$. This inequality reduces to $n_{j}\left(n_{k}+1\right)^{2}<\left[\left(n_{j}-1\right) n_{k}+n_{j}\right]^{2}$. Rearranging this inequality, we must have

$$
\sqrt{n_{j}}\left(\sqrt{n_{j}}-1\right)>n_{k} /\left(1+n_{k}\right)
$$

The right-hand term being strictly lower than 1 (because $n_{k} \geq 2$ ), the inequality is satisfied for any $n_{j} \geq 3$.

\subsection{Proof of Lemma 3}

We have that the sign of $d \delta_{j}^{C}\left(n_{j}\right) / d n_{j}$ is the same as the sign of its numerator which is given by

$$
-\left(3 n_{j}-2\right)\left(n_{j}+1\right)\left(n_{j}^{2}-3 n_{j}+2\right)<0 .
$$

which is indeed negative for any $n_{j} \geq 2$.

The sign of $\partial \delta_{j}^{N}\left(n_{j}, n_{k}\right) / \partial n_{j}$ is the same as the sign of its numerator which can be shown to be given by

$$
-\left(n_{j}+n_{k}\right)\left[\begin{array}{c}
n_{j} n_{k}\left[n_{j}\left(n_{k}+1\right)\left(n_{j}-5\right)+n_{k}^{2}\left(n_{j}-4\right)+7 n_{k}+8\right] \\
+n_{j}\left(n_{j}-1\right)^{2}+n_{k}\left(3 n_{k}^{2}-4 n_{k}-3\right)
\end{array}\right] .
$$

It is immediate to check that the term in brackets is positive for any $n_{k} \geq 2$ and $n_{j} \geq 4$ in which case $\partial \delta_{j}^{N}\left(n_{j}, n_{k}\right) / \partial n_{j}<0$.

Finally, the sign of $\partial \delta_{j}^{N}\left(n_{j}, n_{k}\right) / \partial n_{k}$ for $j \neq k$ is the same as the sign of its numerator which can be shown to be given by

$$
-\left(n_{j}+n_{k}\right)\left[\begin{array}{c}
n_{k}^{2}\left(n_{j}^{4}-3 n_{j}^{3}+n_{j}^{2}+4 n_{j}-3\right) \\
+n_{k}\left(n_{j}^{5}-4 n_{j}^{4}+10 n_{j}^{3}-15 n_{j}^{2}+9 n_{j}-1\right) \\
+\left(n_{j}^{5}-3 n_{j}^{4}+5 n_{j}^{3}-6 n_{j}^{2}+3 n_{j}\right)
\end{array}\right] .
$$

Again, it is immediate to check that the term in brackets is positive for any $n_{j} \geq 4$. By symmetry of the model, this proves Lemma 3. 


\subsection{Proof of Lemma 4}

Let consider the case of group $A$. On the one hand, since $\delta_{A}^{C}\left(n_{A}\right)$ is decreasing in $n_{A}, \delta_{A}^{C}\left(n_{A}\right)$ reaches its minimum when $n_{A}$ goes to infinity. In the limit we have $\lim _{n_{A} \rightarrow \infty} \delta_{A}^{C}\left(n_{A}\right)=1 / 2$. On the other hand, given $n_{B}$, the maximum of $\delta_{A}^{N}\left(n_{A}, n_{B}\right)$ is obtained when the size of group $A$ is at its minimum i.e. when $n_{A}=4$. A sufficient condition for the inequality $\delta_{A}^{N}\left(n_{A}, n_{B}\right)<\delta_{A}^{C}\left(n_{A}\right)$ to be satisfied is then $\delta_{A}^{N}\left(n_{A}=4, n_{B}\right)<1 / 2$. We have $\delta_{A}^{N}\left(n_{A}=4, n_{B}\right)=\frac{\left(n_{B}+4\right)^{2}\left[2 n_{B}+3\right]}{\left(n_{B}+1\right)^{2}\left(11 n_{B}+36\right)}$. Using this expression, the inequality $\delta_{A}^{N}\left(n_{A}=4, n_{B}\right)<1 / 2$, reduces to $7 n_{B}^{3}+20 n_{B}^{2}-29 n_{B}-60>0$ which is always satisfied for any $n_{B} \geq 4$. By symmetry, we also have $\delta_{B}^{C}\left(n_{B}\right)>\delta_{B}^{N}\left(n_{A}, n_{B}\right)$ as stated in Lemma 4.

\subsection{Proof of Lemma 5}

By symmetry and because $\delta_{j}^{C}\left(n_{j}\right)$ (for $j=A, B$ ) only depends on $n_{j}$ and is a decreasing function, we have $\delta_{A}^{C}\left(n_{A}\right) \leq \delta_{B}^{C}\left(n_{B}\right)$ for any $n_{A} \geq n_{B}$. From Lemma 4, we also have $\delta_{A}^{N}\left(n_{A}, n_{B}\right)<\delta_{A}^{C}\left(n_{A}\right)$. Finally, one can find that the sign of $\delta_{A}^{N}\left(n_{A}, n_{B}\right)-\delta_{B}^{N}\left(n_{A}, n_{B}\right)$ is the same as the sign of

$$
\begin{aligned}
& n_{A} n_{B}\left[n_{A}^{2}\left(n_{A}-3\right)-n_{B}^{2}\left(n_{B}-3\right)+\left(n_{A}-n_{B}\right)\left(2 n_{A} n_{B}+5\right)\right] \\
& +n_{A}^{3}\left(n_{A}-4\right)-n_{B}^{3}\left(n_{B}-4\right)+n_{A}\left(n_{A}+2\right)-n_{B}\left(n_{B}+2\right)
\end{aligned}
$$

which is strictly positive for any $n_{A}>n_{B}$ (and equal to 0 for $\left.n_{A}=n_{B}\right)$. Hence, we also have $\delta_{A}^{N}\left(n_{A}, n_{B}\right) \geq$ $\delta_{B}^{N}\left(n_{A}, n_{B}\right)$ which proves Lemma 5.

\section{References}

[1] Axelrod, R.,1981, "The Emergence of Cooperation among Egoists", American Political Science Review $75,306-18$.

[2] Abreu, D., 1986, "Extremal Equilibria of Oligopolistic Supergames", Journal of Economic Theory 39, $191-225$.

[3] Baik, K.H., Lee, S., 2001, "Strategic Groups and Rent Dissipation, Economic Inquiry 39(4), 672-84.

[4] Bendor, J., Mookherjee, D., 1987, "Institutional Structure and the Logic of Ongoing Collective Action," American Political Science Review 81(1), 129-154.

[5] Bornstein, G., Erev, I., Rosen, O., 1990, "Intergroup Competition as a Structural Solution for Social Dilemma," Social Behavior 5, 247-260.

[6] Bornstein, G., Gneezy, U., Nagel, R., 2002, "The Effect of Intergroup Competition on Group Coordination: An Experimental Study," Games and Economic Behavior 41, 1-25. 
[7] Chamberlin, J., 1974, "Provision of Collective Good as a Function of Group Size," American Political Science Review 68, 707-16.

[8] Checchi, D., Lucifora, C., 2002, "Unions and Labor Market Institutions in Europe," Economic Policy $35,363-408$.

[9] Cheikbossian, G., 2009, "The Collective Action Problem: Within-group Cooperation and Between-group Competition in a Repeated Rent-Seeking Game," SSRN Working Paper (http://papers.ssrn.com/sol3/papers.cfm?abstract_id=1115825).

[10] Congleton, R.D., Shugart, W.F., 1990, "The Growth of Social Security: Electoral Push or electoral Pull," Economic Inquiry 28, 109-132.

[11] Davis, C., 2003, Food Fights Over Free Trade: How International Institutions Promote Agricultural Trade Liberalization, Princeton University Press.

[12] Davis, D.D., Reilly, R.J., 1999, "Rent-seeking With Non-identical Sharing Rules: An Equilibrium Rescued," Public Choice 100, 31-38.

[13] Erev, I., Bornstein, G., Galili, R., 1993, "Constructive Intergroup Competition as a Solution to the Free Rider Problem: A Field Experiment," Journal of Experimental Social Psychology 29, 463-478.

[14] Esteban, J. Ray, D., 2001, "Collective Action and the Group Size Paradox," American Political Science Review 95, 663-672.

[15] Friedman, J.W., 1971, "A Non-Cooperative Outcome for Supergames" Review of Economic Studies $38,1-12$.

[16] Gradstein, M., Konrad, K., 1999, "Orchestrating Rent-seeking Contests," Economic Journal 109, $536-545$.

[17] Hardin, R., 1982, Collective Action, Baltimore: John Hopkins University Press.

[18] Hills, F.S., Mahoney, T.A., 1978, "University Budgets and Organizational Decision Making," Administrative Science Quarterly 23, 454-465.

[19] Keeler, J.T., 1996, "Agricultural Power in the European Community: Explaining the Fate of CAP and GATT Negotiations," Comparative Politics 28, 127-149.

[20] Konrad, K., 2009, Strategy and Dynamics in Contests, Oxford University Press..

[21] Kristov, L., Lindert, P., McClelland, R., 1992, "Pressure Groups and Redistribution," Journal of Public Economics 48, 135-63. 
[22] Lambson, V.E., 1984, "Self-Enforcing Collusion in Large Dynamics Markets," Journal of Economic Theory 34(2), 282-91

[23] Lambson, V.E., 1987, "Dynamic Behaviour in Large Markets for Differentiated Products," Review of Economic Studies 54, 293-300.

[24] Leininger, W., Yang, C-L., 1994, "Dynamic Rent-Seeking Games," Games and Economic Behavior 7 , 406-427.

[25] McGuire, M., 1974, "Group Size, Group Homogeneity and the Aggregate Provision of a Pure Public Good under Cournot Behavior," Public Choice 18, 107-26.

[26] Long T., 1998, "The Environmental Lobby" in P. Lowe and S. Ward (Eds.), British Environmental Policy and Europe: Politics and Policy in Transition, Routledge, London.

[27] Nitzan, S., 1991, "Collective Rent Dissipation," Economic Journal 101, 1522-34.

[28] Nti, K.O., 1999, "Rent-seeking with Asymmetric Valuations", Public Choice 98, 415-430.

[29] Olson, M., 1965, The Logic of Collective Action, Cambridge, MA: Harvard University Press.

[30] Olson, M., 1982, The Rise and Decline of Nations, New Haven, Yale University Press.

[31] Pecorino, P., 1998, "Is There a Free-Rider Problem in Lobbying? Endogenous Tariffs, Trigger Strategies, and the Number of Firms," American Economic Review 88, 652-660.

[32] Potters, J., Sloof, R., 1996, "Interest Groups: A Survey of Empirical Models that Try to Assess their Influence," European Journal of Political Economy 12, 403-442.

[33] Rajan, R., Servaes, H., Zingales, L., 2000, "The Cost of Diversity: The Diversification Discount and Inefficient Investment," Journal of Finance 55, 35-80.

[34] Scharfstein, D.S., 1998, "The Dark Side of Internal Capital Markets II: Evidence from Diversified Conglomerates," NBER WP6352.

[35] Skaperdas, S., Gan, L., 1995, "Risk-Aversion in Contests," Economic Journal 105, 951-962.

[36] Skarpedas, S., 1996, "Contest Success Functions," Economic Theory 7, 283-90.

[37] Taylor, M. 1976, Anarchy and Cooperation, Cambridge: Cambridge University Press.

[38] Tullock, G., 1980, "Efficient Rent-seeking," in Buchanan, J.M., Tollison, R.D., and G. Tullock (Eds.), Toward a Theory of the Rent-seeking Society, College Station: Texas A\&M University Press.

[39] Wärneryd, K., 2003, "Information in Conflicts," Journal of Economic Theory 110, 121-136.

[40] Yildirim, H., 2005, "Contests with Multiple Rounds," Games and Economic Behavior 51, 213-27. 